\title{
The CRISPR/Cas9 System for Targeted Genome Engineering in Free-Living Fungi: Advances and Opportunities for Lichenized Fungi
}

\author{
Karthik Shanmugam ${ }^{1,2}$, Sivaprakash Ramalingam ${ }^{3}$, Gayathri Venkataraman ${ }^{1}$ and \\ G. N. Hariharan ${ }^{1 *}$ \\ ${ }^{1}$ M.S. Swaminathan Research Foundation, Chennai, India, ${ }^{2}$ Department of Mycology, University of Bayreuth, Bayreuth, \\ Germany, ${ }^{3}$ CSIR-Institute of Genomics and Integrative Biology, New Delhi, India
}

\section{OPEN ACCESS}

Edited by:

Raffaella Balestrini, Institute for Sustainable Plant

Protection (CNR), Italy

Reviewed by:

Chaoguang Tian,

Tianjin Institute of Industrial

Biotechnology (CAS), China

Todd B. Reynolds,

The University of Tennessee, Knoxville,

United States

${ }^{*}$ Correspondence:

G. N. Hariharan

gnhariharan@mssrf.res.in

Specialty section:

This article was submitted to

Fungi and Their Interactions,

a section of the journal

Frontiers in Microbiology

Received: 25 June 2018

Accepted: 15 January 2019

Published: 07 February 2019

Citation:

Shanmugam K, Ramalingam S,

Venkataraman $G$ and Hariharan GN (2019) The CRISPR/Cas9 System for

Targeted Genome Engineering in

Free-Living Fungi: Advances and

Opportunities for Lichenized Fungi.

Front. Microbiol. 10:62.

doi: 10.3389/fmicb.2019.00062
Studies using whole genome sequencing, computational and gene expression, targeted genome engineering techniques for generating site-specific sequence alterations through non-homologous end joining (NHEJ) by genomic double-strand break (DSB) repair pathway with high precision, resulting in gene inactivation have elucidated the complexity of gene expression, and metabolic pathways in fungi. These tools and the data generated are crucial for precise generation of fungal products such as enzymes, secondary metabolites, antibiotics etc. Artificially engineered molecular scissors, zinc finger nucleases (ZFNs), Transcriptional activator-like effector nucleases (TALENs; that use protein motifs for DNA sequence recognition in the genome) and CRISPR associated protein 9 (Cas9;CRISPR/Cas9) system (RNA-DNA recognition) are being used in achieving targeted genome modifications for modifying traits in free-living fungal systems. Here, we discuss the recent research breakthroughs and developments which utilize CRISPR/Cas9 in the metabolic engineering of free-living fungi for the biosynthesis of secondary metabolites, enzyme production, antibiotics and to develop resistance against post-harvest browning of edible mushrooms and fungal pathogenesis. We also discuss the potential and advantages of using targeted genome engineering in lichenized fungal (mycobiont) cultures to enhance their growth and secondary metabolite production in vitro can be complemented by other molecular approaches.

Keywords: free-living fungi, lichenized fungi, TALENS, CRISPR/Cas9, ZFNs, SSNs, mycobiont culture, transcriptome analysis

\section{INTRODUCTION}

Fungal products are important in agriculture, textile, food, pharmaceutical industries, (Cowan, 2001; Chang and Miles, 2004) and in bioremediation. In nature, fungi play an important role in nutrient cycling, such as decomposition of dead organic matter (Molina et al., 1993; Keizer, 1998; Pilz and Molina, 2001) and act as biofertilizers (Hunt, 1999; Gates et al., 2005). Recent advances in fungal molecular biology have enabled us to sequence complete genomes, and carry out gene and protein expression arrays which further provide opportunities for development of novel products such as mammalian proteins, antibiotics, pigments, and fatty acids for human welfare using fungi (Demain, 1999; Adrio and Demain, 2003; Idnurm and Meyer, 2014). The selection of potential fungal strains for protein and metabolite biosynthesis is made on the basis of production yields and 
regulatory concerns, especially for fungi used in the pharmaceuticals and food industry. Several species of fungi are currently being used for large-scale biosynthesis of recombinant proteins and metabolites (Punt, 2006). Geographically, tropical forests are considered as "treasure-boxes" for fungal biotechnologists due to high levels of fungal biodiversity (Hawksworth and Kalin-Arroyo, 1995). Approximately 20\% of all known fungal species and $\sim 50 \%$ of ascomycetes are obligate symbionts in lichens (fungi that live in symbiotic association with algae or cyanobacteria (Hawksworth and Hill, 1984). Metabolites produced by fungi in particular, are well-known for their therapeutic potential; but a vast resource of these metabolites are unexplored and their potential needs to be tapped. Lichens have been long neglected by mycologists and overlooked by the industry for its relevant novel secondary compounds, its derivatives, proteins and genetic material for the development of useful products. Lichen compounds belong to aliphatic, cyclo-aliphatic, aromatic, and terpenic compound classes and are structurally unique and pharmaceutically relevant (Müller, 2001). Lichen metabolites have been screened for numerous biological activities viz. antiviral, antibiotic, antitumor, allergenic, plant growth inhibitory, anti-herbivore, and enzyme inhibitory properties (Boustie and Grube, 2005). Some compounds were found to have immense potential. The lichen compound diploicin isolated from Buellia canescens, served as a base to derive anilinoaposafranine, an important drug against Mycobacterium tuberculosis (Barry, 1969). Usnic acid, a dibenzofuran isolated from several lichen species was used as a major ingredient in many antibiotics, cosmetics, and sunscreen products (Oran et al., 2016). However, in nature lichens are slow growing, low biomass producing, and also crust forming, making large scale harvest difficult (Balaji et al., 2006). In recent years, mycobiont and whole thallus cultures of several lichen species were established for the biosynthesis of secondary compounds (Valarmathi and Hariharan, 2007; Kinoshita et al., 2015; Molina et al., 2015; Muthukumar et al., 2016; Shanmugam et al., 2016). Cutting edge technologies such as transcriptomics and CRISPR can be used to elucidate gene networks contributing to slow growth rates of mycobionts in culture.

\section{CRISPR/CAS9 SYSTEM IN BACTERIA, ARCHAEA AND EUKARYOTES}

Viruses/phages infect both bacterial and archeal communities that have developed many strategies to evade infection as well as prevent virus adsorption to fend off viral DNA insertion (Horvath and Barrangou, 2010). In 1987, Nakata et al. (1987) discovered curious repeat and non-repeat sequences in the iap gene (Ishino et al., 1987) that are now referred to as Clustered Regular Interspaced Short Palindromic Repeats (CRISPR) (Jansen et al., 2002). Mojica et al. (2005) reported

\footnotetext{
Abbreviations: CAZymes, Carbohydrate Active Enzymes; CRISPR, Clustered regularly interspaced short palindromic repeats; Cas, CRISPR associated proteins; NGS, Next generation sequencing; SSNs, Site specific nucleases; TALENs, Transcriptional activator-like effector nucleases; PAM, Protospacer associated motif; ZFNs; Zinc finger nucleases.
}

that these sequences consist DNA from bacteriophages that were shown to play a role in conferring adaptive bacterial immunity that prevents foreign DNA from being inserted into their genome as well as targets the invasive DNA for destruction. Bolotin et al. (2005) detected the existence of several Cas (CRISPR-associated proteins) genes, which encode DNA endonucleases, suggesting that foreign DNA degradation may be the primary function of CRISPR/Cas9. Three types of CRISPR systems such as Type I, II, and III were identified in 2011, of which the Type II CRISPR system has revolutionized genome editing in eukaryotic cells because of its relative simplicity (Mali et al., 2013). In 2012, Feng Zhang and his co-workers demonstrated its applicability for genome editing in prokaryotes and eukaryotes (Jinek et al., 2012; Cong et al., 2013; Jiang et al., 2013; Doudna and Charpentier, 2014; Nissim et al., 2014; Sander and Joung, 2014). The CRISPR/Cas9 system (Figure 1) is made up of three basic components: CRISPR RNAs (crRNAs), transactivating crRNA (tracrRNA), and CRISPR associated protein (Cas) (Ishino et al., 1987). A single component called synthetic guide RNAs (sgRNA) generated by crRNA and tracrRNA fusion is sufficient to accomplish genome editing in the presence of the Cas endonuclease. The CRIPSR/Cas9 system recognizes DNA through a RNA-DNA interaction between the target site and a CRISPR based synthetic guide RNA. Cas9 nuclease makes double-strand breaks (DSB) at the target site complementary/near complementary to the short 20-nucleotide gRNA present adjacent to the protospaceradjacent motif (PAM) sequence. Both the 20-base-pair (bp) guide sequence on the gRNA and the (PAM) motif, "NGG" present downstream of the unique target sequence determine the specificity of Cas9-mediated DSB (Gasiunas et al., 2012; Jinek et al., 2012). Till date, several publications have reported on effective genetic modifications using CRISPR/Cas9 in several eukaryotic organisms including filamentous fungi (Table 1). The development of a CRISPR/Cas9 system for fungi was first reported in 2013, in Saccharomyces cerevisiae for disruption of the ADE 2, CAN1.Y genes (DiCarlo et al., 2013). After this study was published, gene editing technology was widely applied in several strains of yeast to improve their industrial production by several researchers (Bao et al., 2014; Horwitz et al., 2015; Mans et al., 2015; Stovicek et al., 2015; Fabre Jessop et al., 2016) Schizosaccharomyces pombe (Jake et al., 2015).

\section{DEVELOPMENT OF CRISPR/CAS9 SYSTEM FOR FILAMENTOUS FUNGI AND HIGHER FUNGI}

Similarly CRISPR/Cas9 technology was used to edit the genomes of various filamentous fungi and higher fungi including Ascomycetes and Basidiomycetes and fungus-like eukaryotic microorganisms. Programmable Site-Specific Nucleases for Targeted Genome Engineering in these fungi groups encouragingly have shown promising outcomes (Table 1). For example, the CRISPR/Cas9 system has now been applied and established in several fungal species such as Agaricus bisporus (Waltz, 2016); Aspergillus species (Nødvig 


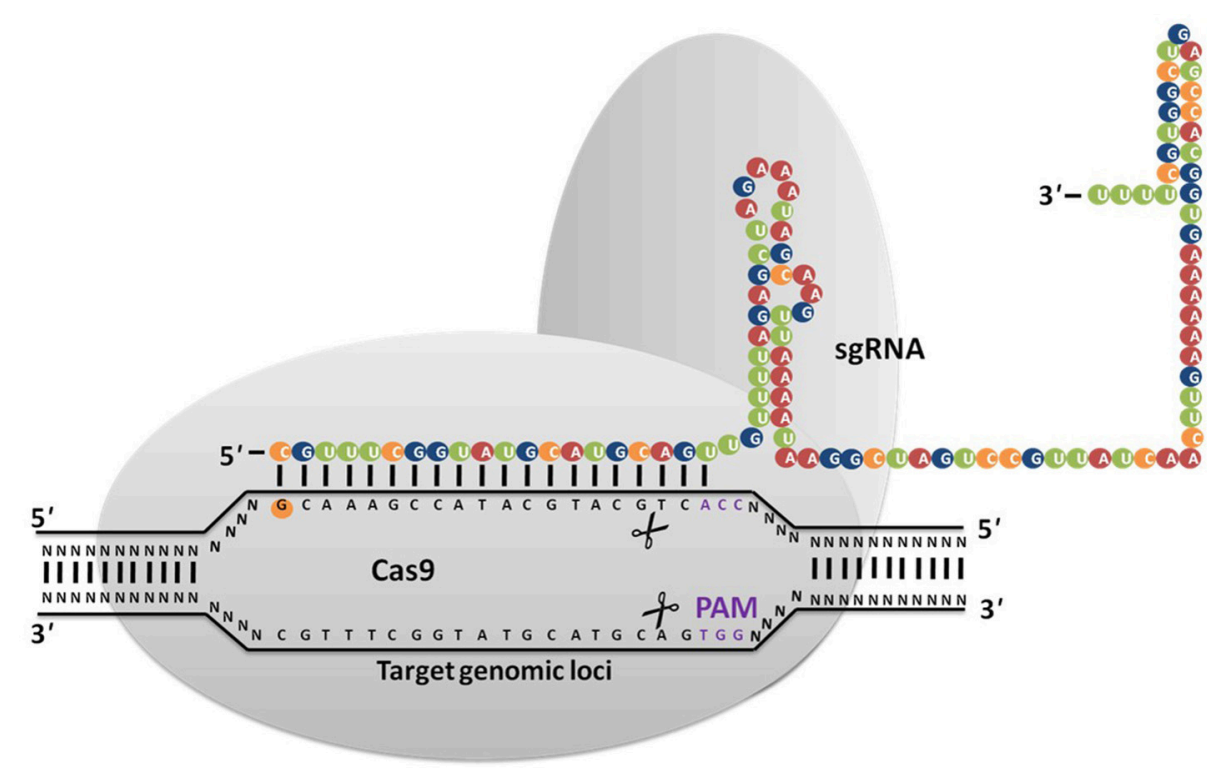

FIGURE 1 | CRISPR/Cas9 system is based on RNA guided engineered nucleases that use complementary base pairing to recognize DNA sequences at target sites. Cas9 protein with nuclease activity induces DSB at the target site via direction of synthetic guide RNA (sgRNA) to the PAM sequence (NGG).

et al., 2015); Myceliophthora (Liu et al., 2017); Neurospora crassa (Matsu-ura et al., 2015), Phytophthora sojae (Fang and Tyler, 2016); Talaromyces atroroseus (Nielsen et al., 2017); Trichoderma reesei (Liu et al., 2015), and Ustilago maydis (Schuster et al., 2016).

\section{APPLICATIONS OF TARGETED GENOME ENGINEERING IN FREE-LIVING FUNGI}

In filamentous fungi, substantial homology lengths $(\sim 1 \mathrm{~Kb})$ with near $100 \%$ homology are required to achieve efficient homologous replacement leading to low recombinational efficiencies (HR; Weld et al., 2006). One strategy to circumvent this would be to increase either the expression of genes involved in promoting $\mathrm{HR}$ or decrease expression of genes involved in non-homologous end joining (NHEJ). In Penicillium chrysogenum, knocking out a gene conferring NHEJ ( hfdA) resulted in efficient disruption of three genes related to betalactam antibiotic biosynthesis (Kück and Hoff, 2010). There was a significant increase in the osmotic sensitivity of the strain, suggesting that there is always some tradeoff that is incurred by disrupting the natural NHEJ process and disruption of NHEJ-related genes, and deficiency in NHEJ activity may promote genomic instability (Zhang and Jasin, 2011). In this background, using gene-editing nucleases that can bring about targeted genome engineering is an alternative advancement to the above-mentioned method and can prove to be a more precise and efficient method for targeted gene modifications in a free-living fungal system. Gene-editing nucleases can be used for experimental exploration of fungal gene function and enhancement of essential traits in economically important fungal species such as biosynthesis of secondary compounds, antibiotics, enzyme production, and increasing shelf life time of edible mushrooms.
Recent advancements in genome sequencing technologies and establishment of transformation protocols for industrially important fungi has now paved the way for fungal biotechnologists to efficiently use engineered nucleases for establishing important free-living fungal species with industrially important desired traits. Gene-editing nucleases are powerful tools for site-specific mutagenesis utilizing either NHEJ mediated repair pathway or homology-directed repair involving transgene integration at a target locus in the fungal genome. The first successful example of targeted genome engineering in fungi using CRISPR/Cas9 system was established in Saccharomyces cerevisiae (DiCarlo et al., 2013).

\section{GENOME EDITING FOR POSTHARVEST BROWNING OF EDIBLE MUSHROOMS}

Rapid postharvest browning of white button mushrooms is a process leads to substantial economic losses. Browning is initiated by enzymatic oxidation of phenols such as tyrosine and non-enzymatic phenol oxidation induced by different factors, including bacteria (Nerya et al., 2006). Knocking out a single polyphenol oxidase gene (PPO) in A. bisporus using CRISPR based deletion of specific bases in PPO results in a $30 \%$ reduction in PPO activity and concomitant reduction in browning. This leads to increased shelf life time of edible mushroom.

\section{GENOME EDITING FOR SECONDARY METABOLITE, ANTIBIOTICS AND ENZYME PRODUCTION}

The potential of fungal secondary metabolism to provide secondary metabolites has until recently been impeded by the 


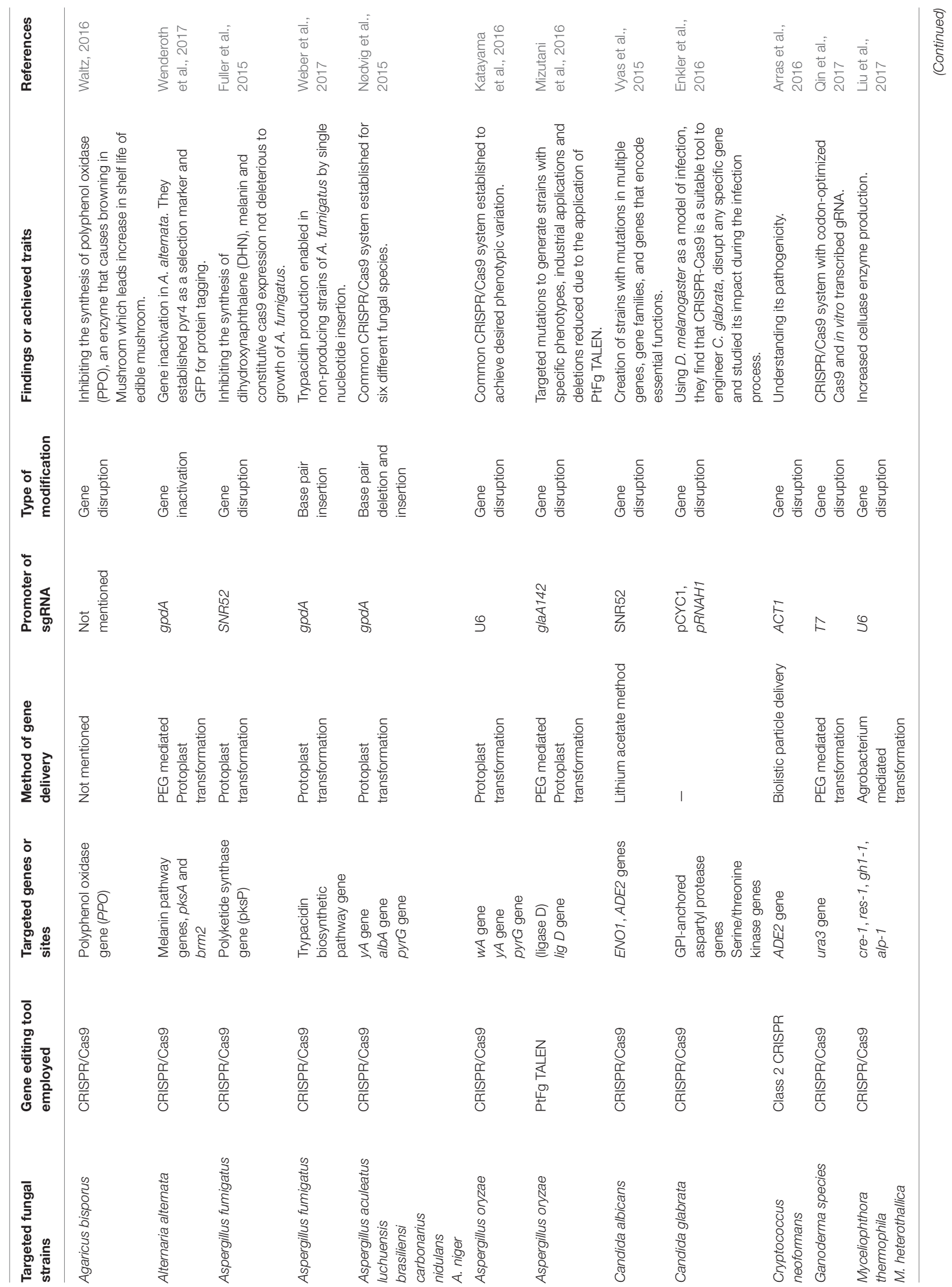




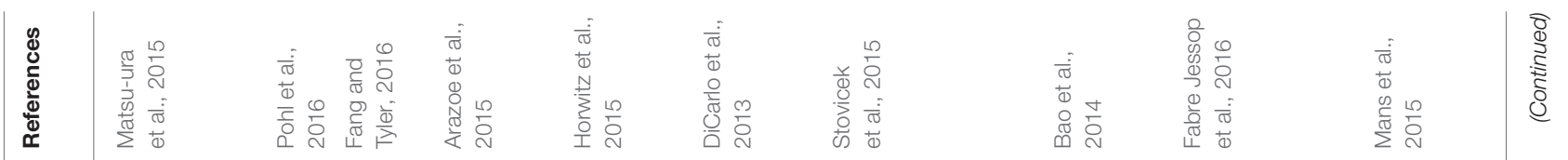

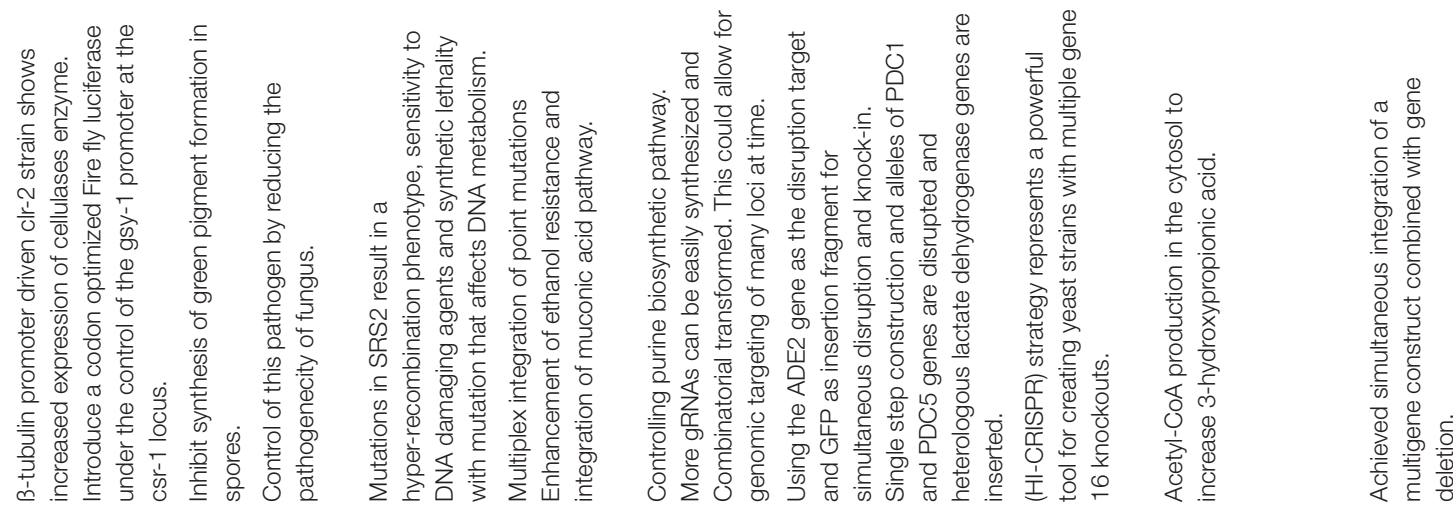

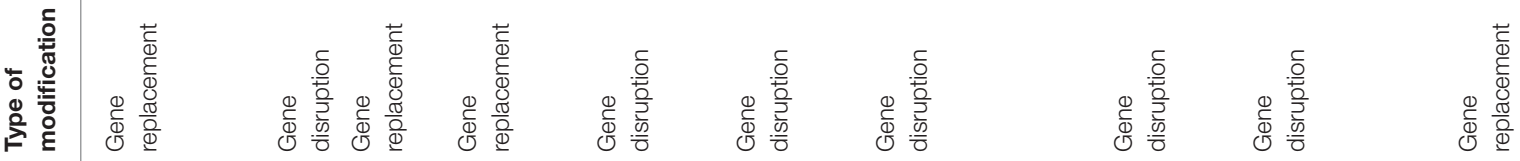

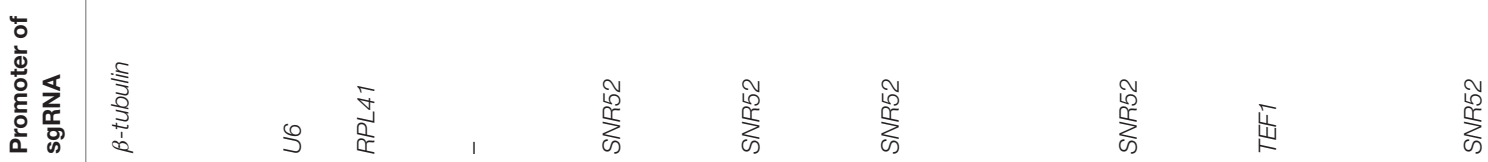
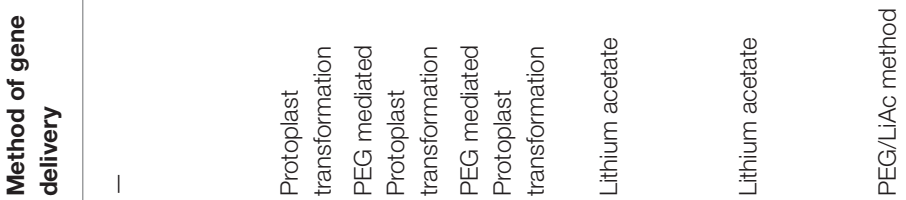

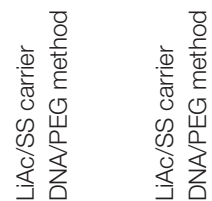

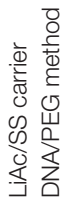

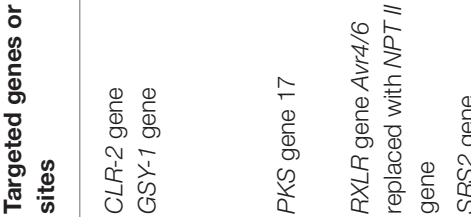

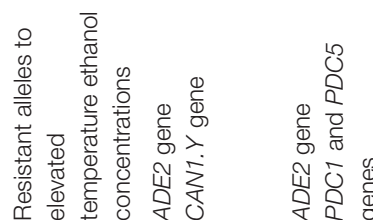
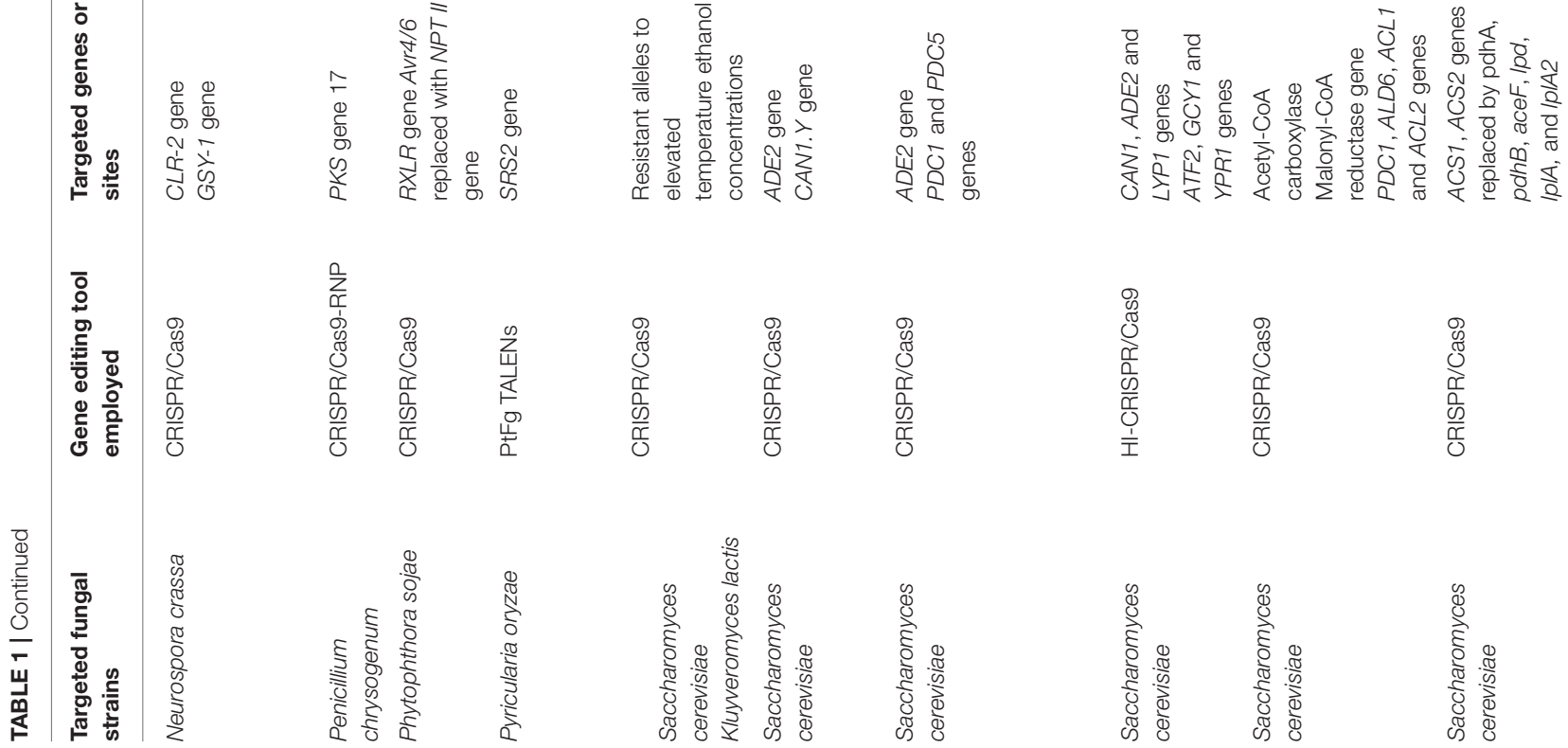

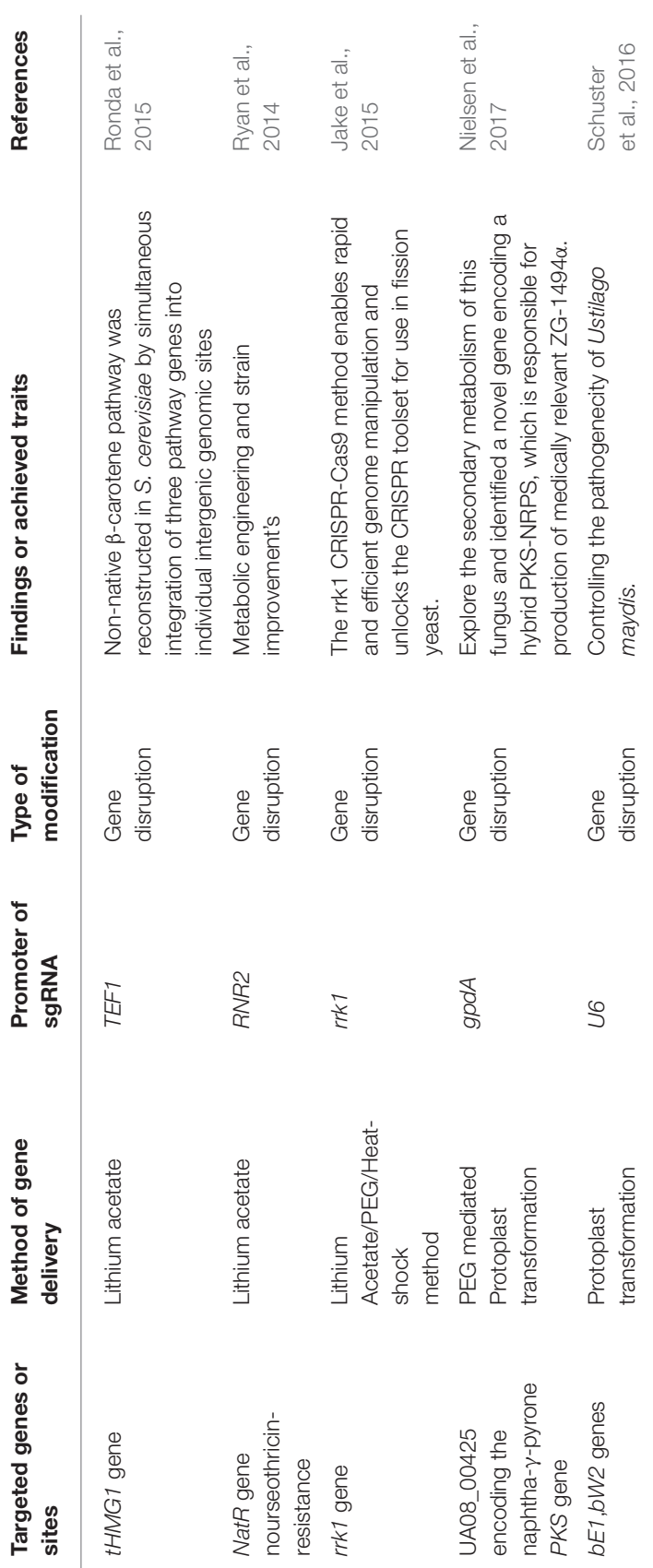

lack of knowledge in available genetic tools for most of the fungal species. However, the emergence of several Site-Specific Nucleases (SSN)-mediated genome engineering technology: TALENs/CRISPR/Cas9-based genome editing systems adapted for several genera of industrially important filamentous fungi species, has now opened doors for future efforts in discovery and biosynthesis of desired quantity of natural products such as secondary metabolites, antibiotics, and enzymes and engineering their biosynthetic pathways for industrial applications. Several studies have reported successful genetic modifications in several eukaryotic organisms including filamentous fungi. For instance, Liu et al. (2015) showed efficient genome editing in filamentous fungus T. reesei using CRISPR/Cas9 system. Furthermore, it was demonstrated that multiple genome modifications can be generated simultaneously in $T$. reesei using CRISPR/Cas9 system. In another study, the Cas9 and sgRNAs were introduced through Agrobacterium mediated transformation (Liu et al., 2015). Recently, Matsu-ura et al. (2015) have shown efficient gene replacement in a model filamentous fungus, Neurospora crassa using CRISPR/Cas9 system. The authors replaced the endogenous promoter of $c l r-2$ with beta-tubulin promoter and introduced codon-optimized fire fly luciferase gene under the control of $g s y-1$ promoter at the clr-2 and csr-1 loci, respectively. The introduced beta-tubulin promoter driven $c l r-2$ strain shows increased expression of cellulase (Matsu-ura et al., 2015). Very recently, Liu et al. (2017) have successfully used the CRISPR/Cas9 system for increasing the production of cellulase in Myceliopthora thermophila and $M$. heterothallica. In this study, the genes cre-1, res-1, gh1-1and alp-1 responsible for synthesizing cellulase were disrupted simultaneously leading to hyper cellulase producing strains. A Cas9-sgRNA RNP mixture targeting the PKS17 gene in P. chrysogenum resulted in absence of green pigment inspores, giving white colonies and a visual screen to examine efficiency of CRISPR mediated gene disruption (Pohl et al., 2016).

In 2016, Jessop-Fabre et al. engineered S. cerevisiae to produce 3-hydroxypropionic acid (3-HP) by inserting genes for 3-HP production (ACC carboxylase and malonyl coA reductase) derived from Chloroflexus aurantiacus using CRISPR coupled with a newly developed EasyClone-Marker Free toolkit. Further upstream engineering to boost cytosolic acetylCoA production to feed into $3-\mathrm{HP}$ production utilizing genes from diverse organisms (Enterococcus faecalis; Pyruvate dehydrogenase complex), Salmonella enterica (PDC1, ALD6 and ACS) and Yarrowia lypotica (ACL1/ACL2 citrate lyase subunits; citrate transporter gene) was also examined using CRISPR. Using this genome engineering vector suite, single and triple insertions are obtained with $90-100$ and $60-70 \%$ targeting efficiency, respectively.

\section{GENOME EDITING OF HUMAN AND PLANT FUNGAL PATHOGENS}

\section{Human Fungal Pathogens}

Fungal pathogens kill more people per year worldwide than malaria or tuberculosis. It is estimated that around 1.6-2 million people are affected every year because of fungal pathogens 
(Denning and Bromley, 2015). Major human pathogenic fungi occur in the genera Cryptococcus, Candida, and Aspergillus, of which the genus Aspergillus causes between 38 and $80 \%$ of fungal disease-associated mortality across the world.

Vyas et al. (2015) have demonstrated development of an efficient codon optimized Cas9 system to target genes in drugresistant clinical isolate strains of diploid Candida. This paves the way to examine mechanisms that render Candida resistant to antifungals using CRISPR technology.

The fungal pathogen Candida glabrata has become the second most common causative agent of candidiasis in the world and it is a major public health concern. Enkler et al. (2016) demonstrated CRISPR/Cas 9 disruption of GPIanchored aspartyl protease and serine/threonine kinase in C. glabrata reduces infectivity in the model invertebrate organism Drosophila melanogaster. Thus, the CRISPR-Cas9 system is a powerful tool to assess the potential role of candidate genes in C. glabrata infectivity. Arras et al. (2016) have demonstrated functionality of the CRISPR construct in Cryptococcus neoformans by disruption of the ADE2 gene. It was also established that Cas9 carrying C. neoformans strains do not affect progression of virulence in a murine inhalation
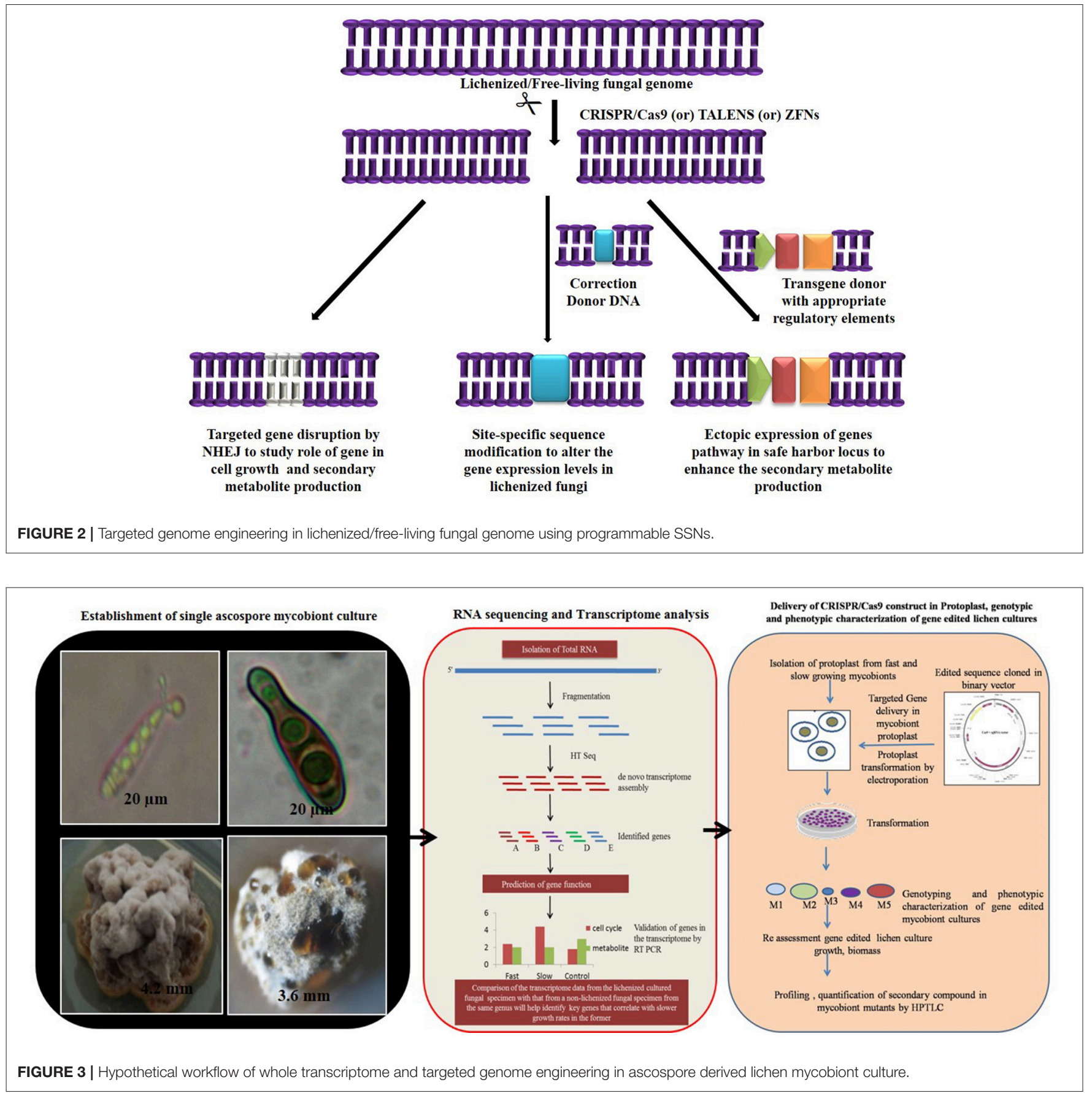
model and is thus a powerful tool to explore mechanisms of C. neoformans pathogenicity.

\section{Plant Fungal Pathogens}

Plant pathogenic fungi extensively damage global crop production, affecting an estimated $10 \%$ of harvested crops impacting food security. Platinum-Fungal TALENs (PtFg TALENs) and CRISPR/Cas9 have now made gene editing possible in fungi (Arazoe et al., 2015; Matsu-ura et al., 2015; Nødvig et al., 2015). PtFg TALENs harbor nonRVD variations at specific residues and have been applied in rice blast fungus Pyricularia oryzae to improve the efficiency of homologous recombination-mediated targeted gene replacement by up to $100 \%$ demonstrating its efficacy for basic and applied biology in filamentous fungi (Arazoe et al., 2015). Using CRISPR/Cas9, the effector Avr $4 / 6$ of the soybean pathogen P. sojae was efficiently knocked out and precisely replaced by the selectable marker nptII, uncovering additional roles for the corresponding $\mathrm{R}$ gene loci, RPS4 and RPS6 in conferring resistance that do not involve recognition through Avr4/6 (Fang and Tyler, 2016). The basidiomycete $U$. maydis is the causative agent of corn smut disease. The utility of the CRISPR/Cas9 system in this fungal pathogen was established by disrupting the homeodomain complex protein encoding genes bE1 and bW2 with a visual phenotypic screen (filamentous) to pick disruptants due to loss of filament formation (Schuster et al., 2016). Establishment of the utility of gene editing tools in plant pathogenic fungus-like eukaryotic microorganisms such $P$. sojae, $P$. oryzae, and $U$. maydis will encourage further refinements in the technology and provide plant breeders and pathologists an additional weapon in their fight against fungal pathogens.

\section{OPPORTUNITIES TO UTILIZE TARGETED GENOME ENGINEERING IN LICHENIZED FUNGI}

The major challenge in culturing lichenized fungi are their slow growth rates in both natural and laboratory culture conditions. Molecular mechanisms contributing to slow growth rates need to be examined as they hinder establishment of mycobiont cultures. Unraveling these mechanisms will help in isolating known and novel bioactive secondary metabolites in desired industrial quantities using established in vitro systems. So far only few lichen forming fungal species have been sequenced for discovery of secondary metabolites and mechanisms conferring drought tolerance and symbiosis (Junttila and Rudd, 2012; Wang et al., 2014). However, there are no reports available regarding molecular mechanisms in lichenized fungi with special reference to factors such as growth inhibiting mechanisms, nutritional choices, key metabolic pathways and compound biosynthesis from the pure mycobiont cultures. Hence, we hypothesize (Figures 2, 3) that whole transcriptome analysis of cultured lichenized fungal species will reveal gene clusters associated with the above key factors. Comparison of the transcriptome data from the lichenized cultured fungal specimen with that from a free-living fungal specimen from the same genus will help identify key genes that correlate with slower growth rates in the former. Subsequently, functional validation of the predicted gene clusters can be achieved through targeted disruption of key genes using cutting-edge CRISPR/Cas9 technology to identify molecular mechanisms controlling growth rates. This will facilitate metabolic engineering of important genes to enhance growth potential of the lichenized mycobiont.

\section{CONCLUSIONS AND FUTURE PERSPECTIVE}

Advancements in Next Generation Sequencing and targeted engineering of genomic regions using site specific nucleases has allowed more reliable targeted genome editing in eukaryotes including fungal genomes. In comparison to conventional genetic methods, CRISPR gene editing technology will provide more rapidly executable tools to carry out functional genomics in filamentous fungal species that target desired traits. This will need to be complemented by genomic (methylome) and small RNA profiling studies that could potentially silence gene clusters to related growth, development and biosynthesis of targeted natural products to realize the full potential of lichenized fungal metabolomics. This also includes exploring regions of the lichenized fungal genome.

\section{AUTHOR CONTRIBUTIONS}

KS, SR, and GH developed the concept and wrote the manuscript. KS and SR designed the schematic figures. GV contributed during revision and provided inputs to improvement the manuscript.

\section{ACKNOWLEDGMENTS}

We thank Prof. M.S. Swaminathan, Founder Chairman, and Executive Director, M.S. Swaminathan Research Foundation, for their constant encouragement and support. Dr. Suja George, Principal Scientist and Dr. G. Ganesan, Assistant Professor for helpful on correcting the language with first version of the manuscript. Mr. G.K. Dayanandham for his help in formatting and proof reading the final version of manuscript. The authors acknowledged Department of Biotechnology, Government of India for the financial support.

\section{REFERENCES}

Adrio, J. L., and Demain, A. L. (2003). Fungal biotechnology. Int.Microbiol. 6, 191-199. doi: 10.1007/s10123-003-0133-0

Arazoe, T., Miyoshi, K., Yamato, T., Ogawa, T., Ohsato, S., Arie, T., et al. (2015). Tailor-made CRISPR/Cas system for highly efficient targeted gene replacement in the rice blast fungus. Biotechnol. Bioeng. 112, 2543-2549. doi: 10.1002/bit.25662 
Arras, S. D. M., Chua, S. M. H., Wizrah, M. S. I., Faint, J. A., Yap, A. S., and Fraser, J. A. (2016). Targeted genome editing via CRISPR in the pathogen Cryptococcus neoformans. PLoS ONE 11:e0164322. doi: 10.1371/journal.pone.01 64322

Balaji, P., Bharath, P., Valarmathi, P., Trupti, M., and Hariharan, G. N. (2006). Lichen bioprospecting-future prospects. J. Swamy Bot. 23, 81-90.

Bao, Z., Xiao, H., Liang, J., Zhang, L., Xiong, X., Sun, N., et al. (2014). Homology-integrated CRISPR-Cas (HI-CRISPR) system for one-step multigene disruption in Saccharomyces cerevisiae. ACS Synth. Biol. 4, 585-594. doi: $10.1021 / \mathrm{sb} 500255 \mathrm{k}$

Barry, V. C. (1969). Synthetic phenazine derivatives and mycobacterial disease: a twenty year investigation. Sci. Proc. R Dublin Soc. Ser. A 3, 153-170.

Bolotin, A., Quinquis, B., Sorokin, A., and Ehrlich, SD. (2005). Clustered regularly interspaced short palindrome repeats (CRISPRs) have spacers of extrachromosomal origin. Microbiology. 151, 2551-2561. doi: 10.1099/mic.0.28048-0

Boustie, J., and Grube, M. (2005). Lichens-a promising source of bioactive secondary metabolites. Plant Genet. Resour. 3, 273-287. doi: 10.1079/PGR200572

Chang, S., and Miles, G P. (2004). Mushrooms: Cultivation, Nutritional Value, Medicinal Effects and Environmental Impact. Boca Raton, FL: CRC Press

Cong, L., Ran, F. A., Cox, D., Lin, S., Barretto, R., Habib, N., et al. (2013). Multiplex genome engineering using CRISPR/Cas systems. Science 33, 819-823. doi: $10.1126 /$ science. 1231143

Cowan, A. (2001). Fungi - life support for ecosystems. Essential ARB 4:1c5. doi: 10.1016/S0065-2296(08)60073-7

Demain, A. L. (1999). Pharmaceutically active secondary metabolites of microorganisms. Appl. Microbiol. Biotechnol. 52, 455-463. doi: $10.1007 / \mathrm{s} 002530051546$

Denning, D. W., and Bromley, M. J. (2015). How to bolster the antifungal pipeline. Science 347, 1414-1416. doi: 10.1126/science.aaa6097

DiCarlo, J. E., Norville, J., Mali, P., Rios, X., Aach, J., and Church, G. M. (2013). Genome engineering in Saccharomyces cerevisiae using CRISPR-Cas systems. Nucleic Acids Res. 41, 4336-4343. doi: 10.1093/nar/gkt135

Doudna, J. A., and Charpentier, E. (2014). The new frontier of genome engineering with CRISPR-Cas9. Science 346:1258096. doi: 10.1126/science.12 58096

Enkler, L., Richer, D., , Marchand, A. L., Ferrandon, D., and Fabrice, J. (2016). Genome engineering in the yeast pathogen Candida glabrata using the CRISPRCas9 system. Sci. Rep. 6, 357-366. doi: 10.1038/srep35766

Fabre Jessop, M. M., Jakočiunas, T., Stovicek, V., Dai, Z., Jensen, M. K., Keasling, J. D., et al. (2016). Easy Clone-Marker Free: a vector toolkit for markerless integration of genes in to Saccharomyces cerevisiae via CRISPR-Cas9. Biotechnol. J. 11, 1110-1117. doi: 10.1002/biot.201600147

Fang, Y., and Tyler, B. M. (2016). Efficient disruption and replacement of an effector gene in the Oomycete Phytophthora sojae using CRISPR/Cas9. Mol. Plant Pathol. 17, 127-139. doi: 10.1111/mpp.12318

Fuller, K. K., Chen, S., Loros, J. J., and Dunlap, J. C. (2015). Development of the CRISPR/Cas9 system for targeted gene disruption in Aspergillus fumigatus. Eukaryot. Cell 14, 1073-1080. doi: 10.1128/EC.00107-15

Gasiunas, G., Barrangou, R., Horvath, P., and Siksnys, V. (2012). Cas9-crRNA ribonucleo protein complex mediates specific DNA cleavage for adaptive immunity in bacteria. Proc. Natl. Acad. Sci. U.S.A. 109, E2579-E2586. doi: 10.1073/pnas.1208507109

Gates, G. M., Ratkowsky, D. A., and Grove, S. J. (2005). A comparison of macrofungi in young silvicultural regeneration and mature forest at the Warra LTER Site in the southern forests of Tasmania. Tasforests 16, 127-152.

Hawksworth, D. L., and Hill, D. J. (1984). The Lichen-Forming Fungi. Tertiary Level Biology Series. Glasgow arid London: Blackie and Son Ltd.

Hawksworth, D. L., and Kalin-Arroyo, M. T. (1995). "Magnitude and distribution of biodiversity," in Global Biodiversity Assessment, ed V. H. Heywood (Cambridge: Cambridge University Press), 107-191.

Horvath, P., and Barrangou, R. (2010). CRISPR/Cas, the immune system of bacteria and archaea. Science 327, 167-170. doi: 10.1126/science.1179555

Horwitz, A. A., Walter, J. M., Schubert, M. G., Kung, SH., Hawkins, K., Platt, D. M., et al. (2015). Efficient multiplexed integration of synergistic alleles and metabolic pathways in yeasts via CRISPR-Cas. Cell Syst. 1, 88-96. doi: 10.1016/j.cels.2015.02.001
Hunt, G. A. (1999). "Assessing macrofungi of special concern for conservation in Forested ecosystems," in Proceedings of Biology and Management of Species and Habitats at Risk (Victoria, BC), 779-780.

Idnurm, A., and Meyer, V. (2014). Welcome to Fungal biology and biotechnology. Fungal Biol. Biotech. 1, 8-9. doi: 10.1186/s40694-014-0008-5

Ishino, Y., Shinagawa, H., Makino, K., Amemura, M., and Nakata, A. (1987). Nucleotide sequence of the iap gene, responsible for alkaline phosphatase isozyme conversion in Escherichia coli, and identification of the gene product. J. Bacteriol. 169, 5429-5433. doi: 10.1128/jb.169.12.5429-5433.1987

Jake, Z. J., Keith, M. C., Vincent, T., and Mikel, Z. (2015). Implementation of the CRISPR-Cas9 system in fission yeast. Nat. Commun. 5:5344. doi: $10.1038 /$ ncomms6344

Jansen, R., Embden, J. D., Gaastra, W., and Schouls, L. M. (2002). Identification of genes that are associated with DNA repeats in prokaryotes. Mol. Microbiol. 43, 1565-1575. doi: 10.1046/j.1365-2958.2002.02839.x

Jiang, W., Bikard, D., Cox, D., Zhang, F., and Marraffini, L. A., (2013). RNA-guided editing of bacterial genomes using CRISPR-Cas systems. Nat. Biotechnol. 31 233-239. doi: 10.1038/nbt.2508

Jinek, M., Chylinski, K., Fonfara, I., Hauer, M., Doudna, J. A., and Charpentier, E. (2012). A programmable dual-RNA- guided DNA endonuclease in adaptive bacterial immunity. Science 337, 816-821. doi: 10.1126/science.1225829

Junttila, S., and Rudd, S. (2012). Characterization of a transcriptome from a nonmodel organism Cladonia rangiferina, the grey reindeer lichen, using highthroughput next generation sequencing and EST sequence data. BMC Genomics 13:575. doi: 10.1186/1471-2164-13-575

Katayama, T., Tanaka, Y., Okabe, T., Nakamura, H., Fujii, W., Kitamoto, K., et al. (2016). Development of a genome editing technique using the CRISPR/Cas9 system in the industrial filamentous fungus Aspergillus oryzae. Biotechnol. Lett. 38, 637-642. doi: 10.1007/s10529-015-2015-x

Keizer, G. J. (1998). The Complete Encyclopedia of Mushrooms. Lisses: Rebo.

Kinoshita, K., Fukumaru, M., Yamamoto, Y., Koyama, K., and Takahashi, K. (2015). Biosynthesis of panaefluoroline B from the cultured mycobiont of Amygdalaria panaeola. J. Nat. Prod. 78, 1745-1747. doi: 10.1021 acs.jnatprod.5b00055

Kück, U., and Hoff, B. (2010). New tools for the genetic manipulation of filamentous fungi. Appl. Microbiol. Biotechnol. 86:5162. doi: 10.1007/s00253-009-2416-7

Liu, Q., Ranran, G., Jingen, L., Liangcai, L, Junqi, Z., Wenliang, S., et al. (2017). Development of a genome-editing CRISPR/Cas9 system in thermophilic fungal Mycelioph thora species and its application to hyper-cellulase production strain engineering. Biotechnol. Biofuels 10:1. doi: 10.1186/s13068-016-0693-9

Liu, R., Ling, C., Yanping, J., Zhihua, Z., and Gen, Z. (2015). Efficient genome editing in filamentous fungus Trichoderma reesei using the CRISPR/Cas9 system. Cell Discov. 1:15007. doi: 10.1038/celldisc.2015.7

Mali, P., Yang, L., Esvelt, K. M., Aach, J., Guell, M., DiCarlo, J. E., et al. (2013). RNA-guided human genome engineering via Cas9. Science. 339:823. doi: $10.1126 /$ science. 1232033

Mans, R., Harmen, M. R., Melanie, W., Backx, A., Niels, G. A., van Kuijpers, B. M., et al. (2015). CRISPR/Cas9: a molecular Swiss army knife for simultaneous introduction of multiple genetic modifications in Saccharomyces cerevisiae. FEMS Yeast Res. 15:fov004. doi: 10.1093/femsyr/fov004

Matsu-ura, T., Baek, M., Kwon, J., and Hong, C. (2015). Efficient gene editing in Neurospora crassa with CRISPR technology. Fungal Biol. Biotechnol. 2:4. doi: 10.1186/s40694-015-0015-1

Mizutani, O., Arazoe, T., Toshida, K., Hayashi, R., Ohsato, S., Sakuma, T., et al. (2016). Detailed analysis of targeted gene mutations caused by the PlatinumFungal TALENs in Aspergillus oryzae RIB40 strain and a ligD disruptant. J. Biosci. Bioeng. 123, 287-293. doi: 10.1016/j.jbiosc.2016.09.014

Mojica, F. J., Díez-Villaseñor, C., García-Martínez, J., and Soria, E. (2005). Intervening sequences of regularly spaced prokaryotic repeats derive from foreign genomic elements. J. Mol. Evol. 60, 174-182. doi: 10.1007/s00239-004-0046-3

Molina, M. C., Divakar, P. K., and González, N. (2015). Success in the isolation and axenic culture of Anaptychia ciliaris (Physciaceae, Lecanoromycetes) mycobiont. Mycoscience 56, 351-358. doi: 10.1016/j.myc.2014.10.003

Molina, R., O’Dell, T., Luoma, D., Amaranthus, M., and Castellano, R. K. (1993). Biology, Ecology and Social Aspects of Wild Edible Mushrooms in the Forests of the Pacific Northwest: A Preface of Managing Commercial Harvest. 
Portland, OR: U. S. Department of Agriculture Forest service, Pacific Northwest Research Station.

Müller, K. (2001). Pharmaceutically relevant metabolites from lichens. Appl. Microbiol. Biotechnol. 56, 9-16. doi: 10.1007/s002530100684

Muthukumar, S., Karthik, S., and Hariharan, G. N. (2016). Mycobiont and whole thallus cultures of Roccella montagnei Bél. For the biosynthesis of secondary compounds. Crypt. Biodivers. Assess. 1, 15-20. doi: 10.21756/cba.v0i.11014

Nakata, A., Shinagawa, H., and Rothman, F. G. (1987). "Molecular mechanism of isozyme formation of alkaline phosphatase in Escherichia coli", in Phosphate Metabolism and Cellular Regulation in Microorganisms, eds A. Torriani, F. Rothman, S. Silver, A. Wright, and E. Yagil (Washington, DC: American Society for Microbiology), 139-141.

Nerya, O., Arie, R. B., Luzzatto, T., Musa, R., Khativ, S., and Vaya, J. (2006). Prevention of Agaricus bisporus postharvest browning with tyrosinase inhibitors. Postharvest Biol. Technol. 39, 272-277. doi: 10.1016/j.postharvbio.2005.11.001

Nielsen, M. L., Isbrandt, T., Rasmussen, K. B., Thrane, U., Hoof, J. B., Larsen, T. O. L., et al. (2017). Genes linked to production of secondary metabolites in Talaromyces atroroseus revealed using CRISPR-Cas9. PLoS ONE 12:e0169712. doi: 10.1371/journal.pone.0169712

Nissim, L., Perli, S. D., Fridkin, A., Perez-Pinera, P., and Lu, T. K. (2014). Multiplexed and programmable regulation of gene networks with an integrated RNA and CRISPR/Cas toolkit in human cells. Mol. Cell 54, 698-710. doi: 10.1016/j.molcel.2014.04.022

Nødvig, C. S., Nielsen, J. B., Kogle, M. E., and Mortensen, U. H. (2015). A CRISPR-Cas9 system for genetic engineering of filamentous fungi. PLoS ONE 10:e0133085. doi: 10.1371/journal.pone.0133085

Oran, S., Sahin, S., Sahinturk, P., Ozturk, S., and Demir, C. (2016). Antioxidant and antimicrobial potential, and HPLC analysis of stictic and usnic acids of three Usnea species from Uludag mountain (Bursa, Turkey). Iran. J. Pharm. Res. 15, $527-535$.

Pilz, D., and Molina, R. (2001). Commercial harvests of Edible Mushrooms from the forests of the Pacific Northwest United States: issues, management and monitoring for sustainability. For. Ecol. Manage. 155, 3-16. doi: 10.1016/S0378-1127(01)00543-6

Pohl, C., Kiel, J. A., Driessen, A. J., Bovenberg, R. A, and Nygárd, Y. (2016). CRISPR/Cas9 based genome editing of Penicillium chrysogenum. ACS Synth. Biol. 5, 754-764. doi: 10.1021/acssynbio.6b00082

Punt, P. (2006). Filamentous fungi as cell factories for protein production. Microb. Cell Fact. 5:S32. doi: 10.1186/1475-2859-5-S1-S32

Qin, H., Han, X., Gen, Z., Zhihua, Z., and Jian-Jiang, Z. (2017). CRISPR-Cas9 assisted gene disruption in the higher fungus Ganoderma species. Process Biochem. 56, 57-61. doi: 10.1016/j.procbio.2017.02.012

Ronda, C., Maury, J., Tadas, J., Simo, A. B. J., Susanne, M. G., Scott, J. H., et al. (2015). CrEdit: CRISPR mediated multi-loci gene integration in Saccharomyces cerevisiae. Microb. Cell Fact. 14:97. doi: 10.1186/s12934-015-0288-3

Ryan, O. W., Skerker, J. M., Maurer, M. J., Li, X., Tsai, J. C., Poddar, S., et al. (2014). Selection of chromosomal DNA libraries using a multiplex CRISPR system. eLife 3:3703. doi: 10.7554/eLife.03703
Sander, J. D., and Joung, J. K. (2014). CRISPR-Cas systems for editing, regulating and targeting genomes. Nat. Biotechnol. 32, 347-355. doi: 10.1038/nbt.2842

Schuster, M., Schweizer, G., Reissmann, S., and Kahmann, R. (2016). Genome editing in Ustilago maydis using the CRISPR-Cas system. Fungal Genet. Biol. 89, 3-9. doi: 10.1016/j.fgb.2015.09.001

Shanmugam, K., Srinivasan, M., and Hariharan, G. N. (2016). Developmental stages and secondary compound biosynthesis of mycobiont and whole thallus cultures of Buellia subsororioides. Mycol. Prog. 15:41. doi: 10.1007/s11557-016-1184-x

Stovicek, V., Borodina, I., and Forster, J. (2015). CRISPR-Cas system enables fast and simple genome editing of industrial Saccharomyces cerevisiae strains. Metab. Eng. Commun. 2, 13-22. doi: 10.1016/j.meteno.2015.03.001

Valarmathi, R., and Hariharan, G. N. (2007). Soredial culture of Dirinaria applanata (Fée) Awasthi: observations on developmental stages and compound production. Symbiosis 43, 137-142.

Vyas, V. K., Barrasa, M. I., and Fink, G. R. (2015). A Candida albicans CRISPR system permits genetic engineering of essential genes and gene families. Sci. Adv. 1, 1500248-1500248. doi: 10.1126/sciadv.1500248

Waltz, E. (2016). Gene-edited CRISPR mushroom escapes US regulation. Nature 532:293. doi: 10.1038/nature.2016.19754

Wang, Y.-Y., Liu, B., Zhang, X.-Y., Zhou, Q.-M., Zhang, T., Li, H., et al. (2014). Genome characteristics reveal the impact of lichenization on lichenforming fungus Endocarpon pusillum Hedwig (Verrucariales, Ascomycota). BMC Genomics 15:34. doi: 10.1186/1471-2164-15-34

Weber, J., Valiante, V., Nødvig, C. S., Mattern, D. J., Slotkowski, R. A., Mortensen, U. H., et al. (2017). Functional reconstitution of fungal natural product gene cluster by advance genome editing. ACS Synth. Biol. 6, 62-68. doi: $10.1021 /$ acssynbio.6b00203

Weld, R. J., Plummer, K. M., Carpenter, M.A, and Ridgway, H. J. (2006). Approaches to functional genomics in filamentous fungi. Cell Res. 16, 31-44. doi: 10.1038/sj.cr.7310006

Wenderoth, M., Pinecker, C., Voß, B., and Fischer, R. (2017). Establishment of CRISPR/Cas9 in Alternaria alternata. Fungal Genet. Biol. 101, 55-60. doi: 10.1016/j.fgb.2017.03.001

Zhang, Y., and Jasin, M. (2011). An essential role for CtIP in chromosomal translocation formation through an alternative end-joining pathway. Nat. Struct. Mol. Biol. 18,80-84. doi: 10.1038/nsmb.1940

Conflict of Interest Statement: The authors declare that the research was conducted in the absence of any commercial or financial relationships that could be construed as a potential conflict of interest.

Copyright (c) 2019 Shanmugam, Ramalingam, Venkataraman and Hariharan. This is an open-access article distributed under the terms of the Creative Commons Attribution License (CC BY). The use, distribution or reproduction in other forums is permitted, provided the original author(s) and the copyright owner(s) are credited and that the original publication in this journal is cited, in accordance with accepted academic practice. No use, distribution or reproduction is permitted which does not comply with these terms. 